\title{
MORFOLOGIA DE PARAFINAS DE ÓLEOS CRUS E SISTEMAS MODELO POR MEIO DE MICROSCOPIA
}

\author{
A. C. P. DUNCKE, C. N. BARBATO e M. NELE \\ Universidade Federal do Rio de Janeiro - UFRJ. Departamento de Engenharia Química - Escola de \\ Química \\ E-mail para contato: angeladuncke@ hotmail.com
}

\begin{abstract}
RESUMO - A maior parte da produção de petróleo brasileiro é proveniente de campos offshore, inclusive de poços localizados em águas profundas da camada pré-sal. Esta produção, entretanto tem enfrentado problemas com relação à deposição de parafinas nos dutos de transporte. Os óleos localizados em águas profundas passam por um processo de resfriamento natural devido às baixas temperaturas do mar, cerca de $4^{\circ} \mathrm{C}$. A combinação de baixas temperaturas e óleos parafínicos ocasiona a precipitação e deposição nos dutos de escoamento promovendo obstruções totais e/ou parciais. Pouco se sabe sobre as relações entre as taxas de resfriamento, comportamento reológico e morfologia de parafinas, bem como as interações das cadeias parafínicas com água ou outros componentes do petróleo. Assim, este trabalho tem como objetivo caracterizar a estrutura das parafinas presentes no petróleo, bem como parafinas isoladas solubilizadas em uma matriz inerte, por meio de microscopia de luz transmitida. A morfologia observada das parafinas do petróleo cru e do sistema modelo solubilizada na matriz inerte apresenta estruturas relativamente semelhantes nas mesmas condições experimentais.
\end{abstract}

\section{INTRODUÇÃO}

Segundo dados do Anuário Estatístico Brasileiro do Petróleo, Gás Natural e Biocombustíveis do ano de 2013, o Brasil produziu 754,4 milhões de barris de petróleo no ano de 2012, sendo 66,04 milhões de barris oriundos de campos onshore e 688,4 milhões provenientes de campos offshore. A produção offshore, entretanto tem enfrentado problemas com relação à deposição de parafinas em dutos de transporte.

Os petróleos da camada pré-sal são parafínicos e passam por um processo de resfriamento natural devido às baixas temperaturas marinhas (cerca de $4^{\circ} \mathrm{C}$ ). Estas condições favorecem a precipitação e deposição das moléculas de parafina nos dutos de escoamento promovendo obstruções totais e/ou parciais. Estas deposições ocorrem quando a temperatura da linha encontra-se abaixo da temperatura inicial de aparecimento dos cristais (TIAC) e, se tornam mais críticas conforme ocorre a diminuição gradual da temperatura.

Segundo Hammami e Raines (1999), as parafinas são cadeias longas de hidrocarbonetos, 


\section{9 a 22 de outubro de 2014 \\ Florianópolis/SC}

contendo entre 15 e 75 carbonos. Estas moléculas têm seus átomos de carbono dispostos em cadeias lineares (n-parafinas), ou podem apresentar ramificações (isoparafinas).

Geralmente a temperatura inicial de aparecimento dos cristais está na faixa de 25 a $50^{\circ} \mathrm{C}$. (KANÉ et al, 2003). Segundo Létoffe et al. (1995), a TIAC de uma amostra aumenta conforme aumentam-se o número de carbonos das cadeias parafínicas, e a porcentagem de parafinas no óleo. Isso significa que, óleos crus com alto teor de parafinas e/ou compostos majoritariamente por cadeias carbônicas mais longas, apresentam maiores valores de TIAC que óleos com predominância de cadeias mais curtas e/ou baixos teores de parafinas.

De acordo com Kané et al. (2003) o tamanho dos cristais de parafina formados é diretamente dependente do tamanho da cadeia carbônica. Cadeias maiores geram cristais maiores, bem como cadeias menores formam cristais menores. Os cristais formados geralmente têm seu tamanho entre $1 \mathrm{e}$ $3 \mu \mathrm{m}$.

As parafinas podem cristalizar basicamente em duas estruturas: ortorrômbica ou hexagonal. A forma ortorrômbica se assemelha ao modelo de bastões e é encontrada em óleos crus com alto teor de parafinas. Para parafinas isoladas solubilizadas em uma matriz, tem-se preferencialmente a estrutura hexagonal, que se assemelha a placas. (KANÉ et al, 2003).

O principal objetivo deste trabalho é caracterizar a estrutura das parafinas presentes no petróleo por meio de: microscopia de luz transmitida, testes de densidade, determinação da TIAC, determinação das frações de água, saturados, aromáticos, resinas e asfaltenos. Busca-se ainda, verificar e comparar amostras de petróleo bruto com parafinas isoladas solubilizadas em uma matriz inerte.

\section{PROCEDIMENTOS}

A fim de verificar a morfologia das parafinas precipitadas selecionaram-se dois tipos de amostras: óleo parafínico cru, cedido pela Petrobras, e parafinas isoladas, da Vetec química fina. $\mathrm{O}$ sistema modelo foi preparado $5 \%$ de parafinas solubilizadas (em massa) em uma matriz inerte. A matriz inerte consiste em um óleo parafínico chamado Spindle branco, da Petrobras.

Ao utilizar amostras de petróleo bruto, deve-se inicialmente apagar o histórico térmico das mesmas a fim de eliminar qualquer vestígio de parafinas precipitadas, extinguindo os núcleos de crescimento de cristais provenientes de cristalizações anteriores (LI e ZHANG, 2003 e PEDERSON e RONNINGSEN, 2000). Para isso selecionou-se uma alíquota de petróleo de aproximadamente $100 \mathrm{~mL}$, que foi aquecida a $80^{\circ} \mathrm{C}$ por duas horas.

Já para parafinas isoladas solubilizadas em Spindle, a etapa de remoção do histórico térmico não foi realizada. A parafina foi adicionada à matriz e aquecida a $80^{\circ} \mathrm{C}$ por apenas dez minutos para que fosse completamente solubilizada. Acredita-se que esta diferença de tempo de aquecimento das amostras deve-se as suas naturezas distintas, pois as parafinas do petróleo estão sujeitas as interações entre os diversos componentes do óleo (asfaltenos, aromáticos, resinas, sólidos, etc.), enquanto que as 
isoladas não sofrem este tipo de interação.

Após a etapa de solubilização da parafina, as amostras passaram para a etapa de resfriamento controlado de $80^{\circ} \mathrm{C}$ a $5^{\circ} \mathrm{C}$, cuja taxa de resfriamento utilizada era $0,7^{\circ} \mathrm{C} / \mathrm{min}$. Após atingir $5^{\circ} \mathrm{C}$ as amostras foram mantidas no refrigerador por 24 horas a fim de verificar o crescimento dos cristais.

Durante todo processo de resfriamento retiraram-se gotas das amostras para observação microscópica nas temperaturas: $80^{\circ} \mathrm{C}, 50^{\circ} \mathrm{C}, 30^{\circ} \mathrm{C}, 20^{\circ} \mathrm{C}, 10^{\circ} \mathrm{C}$ e $5^{\circ} \mathrm{C}$, e nos tempos $30 \mathrm{~min}, 1 \mathrm{~h}, 2 \mathrm{~h}, 3 \mathrm{~h}$ e $24 \mathrm{~h}$ de resfriamento na geladeira (temperatura da geladeira $\approx 1^{\circ} \mathrm{C}$ ). $\mathrm{O}$ microscópio utilizado foi o modelo Axiovert 40 MAT, da fabricante Carl Zeiss,.

As técnicas utilizadas para a caracterização do petróleo parafínico cru foram as seguintes: 1) determinação da TIAC por meio do método de calorimetria exploratória diferencial (DSC Differential Scanning Calorimeter) na faixa de temperatura de $80^{\circ} \mathrm{C}$ a $-10^{\circ} \mathrm{C}$ e com taxa de resfriamento de $1^{\circ} \mathrm{C} / \mathrm{min}$, no equipamento Pyris Diamond da Perkin-Elmer; 2) determinação das frações de saturados, aromáticos, resinas e asfaltenos (SARA) por meio de um sistema de cromatografia de camada fina e detecção por ionização de chama (TLC-FID - thin layer chromatography flame ionization detection); 3) medida da densidade a $25^{\circ} \mathrm{C}$ e a $4^{\circ} \mathrm{C}$ no densímetro e viscosímetro Anton Par SVM 3000 Stabinger; 4) obtenção da fração mássica de água presente por meio de titulação potenciométrica Karl Fisher (KF) no equipamento KF Metrohm 836.

\section{RESULTADOS}

As características analisadas do petróleo parafínico encontram-se na Tabela 1.

Tabela 1 - Características da amostra de petróleo parafínico cru

\begin{tabular}{l|l}
\hline Amostra & Petróleo parafínico \\
\hline \multirow{4}{*}{ SARA } & Saturados: $63,1 \% \mathrm{~m} / \mathrm{m}$ \\
\cline { 2 - 2 } & Aromáticos: $18,2 \% \mathrm{~m} / \mathrm{m}$ \\
\cline { 2 - 2 } & Resinas: $18,6 \% \mathrm{~m} / \mathrm{m}$ \\
\cline { 2 - 2 } TIAC & Asfaltenos: $<0,5 \% \mathrm{~m} / \mathrm{m}$ \\
\hline \multirow{2}{*}{ Densidade } & $1^{\circ}$ evento: $37,58^{\circ} \mathrm{C}$ \\
\cline { 2 - 2 } & $2^{\circ}$ evento: $17,90^{\circ} \mathrm{C}$ \\
\hline Fração de $\mathbf{H}_{2} \mathbf{O}$ & $25^{\circ} \mathrm{C}: 0,871 \mathrm{~g} / \mathrm{cm}^{3}$ \\
\cline { 2 - 2 } & $4^{\circ} \mathrm{C}: 0,886 \mathrm{~g} / \mathrm{cm}^{3}$ \\
\hline
\end{tabular}

A Figura 1 apresenta as microscopias da amostra de petróleo parafínico durante o resfriamento $\left(80^{\circ} \mathrm{C}\right.$ a $\left.5^{\circ} \mathrm{C}\right)$ e a respectiva ampliação da imagem. 


\section{9 a 22 de outubro de 2014 \\ Florianópolis/SC}

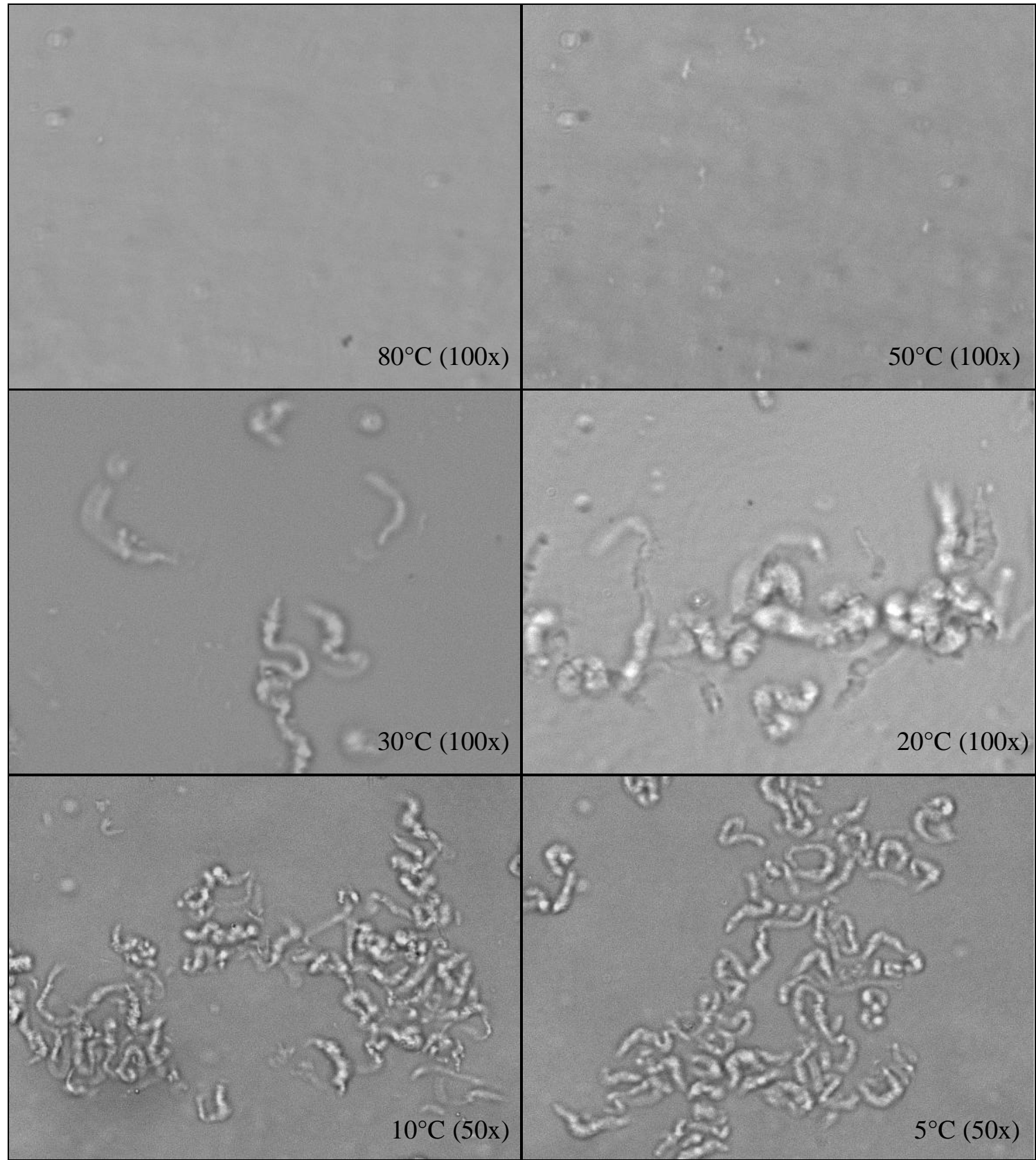

Figura 1 - Precipitação de parafinas de óleo parafínico durante processo de resfriamento a $0,7^{\circ} \mathrm{C} / \mathrm{min}$, de $80^{\circ} \mathrm{C}$ a $5^{\circ} \mathrm{C}$.

Verifica-se o aumento de precipitados com a redução da temperatura para o óleo parafínico. Os cristais apresentam formas alongadas, conforme proposto na literatura (KANÉ et al, 2003). A superfície dos cristais tem aparência rugosa, entretanto esta característica só poderá ser confirmada com a utilização de outras técnicas de microscopia (eletrônica de transmissão ou força atômica) 
(ZBIK et al. 2006. e KANÉ et al, 2003). Nota-se que o início da precipitação encontra-se entre $50^{\circ} \mathrm{C}$ e $30^{\circ} \mathrm{C}$, concordando com o primeiro evento da TIAC obtida pelo método de DSC $\left(37,58^{\circ} \mathrm{C}\right)$ como mostrado na Tabela 1.

A Figura 2 apresenta as imagens obtidas após a inserção da amostra no refrigerador (de 30 minutos a 24 horas) e a respectiva ampliação da imagem. Observa-se nas imagens de 30 min e $24 \mathrm{~h}$, que apresentam a mesma ampliação, o aumento da quantidade de parafinas precipitadas. Nota-se que com o passar do tempo as parafinas se aglomeram formando "redes" de parafinas.

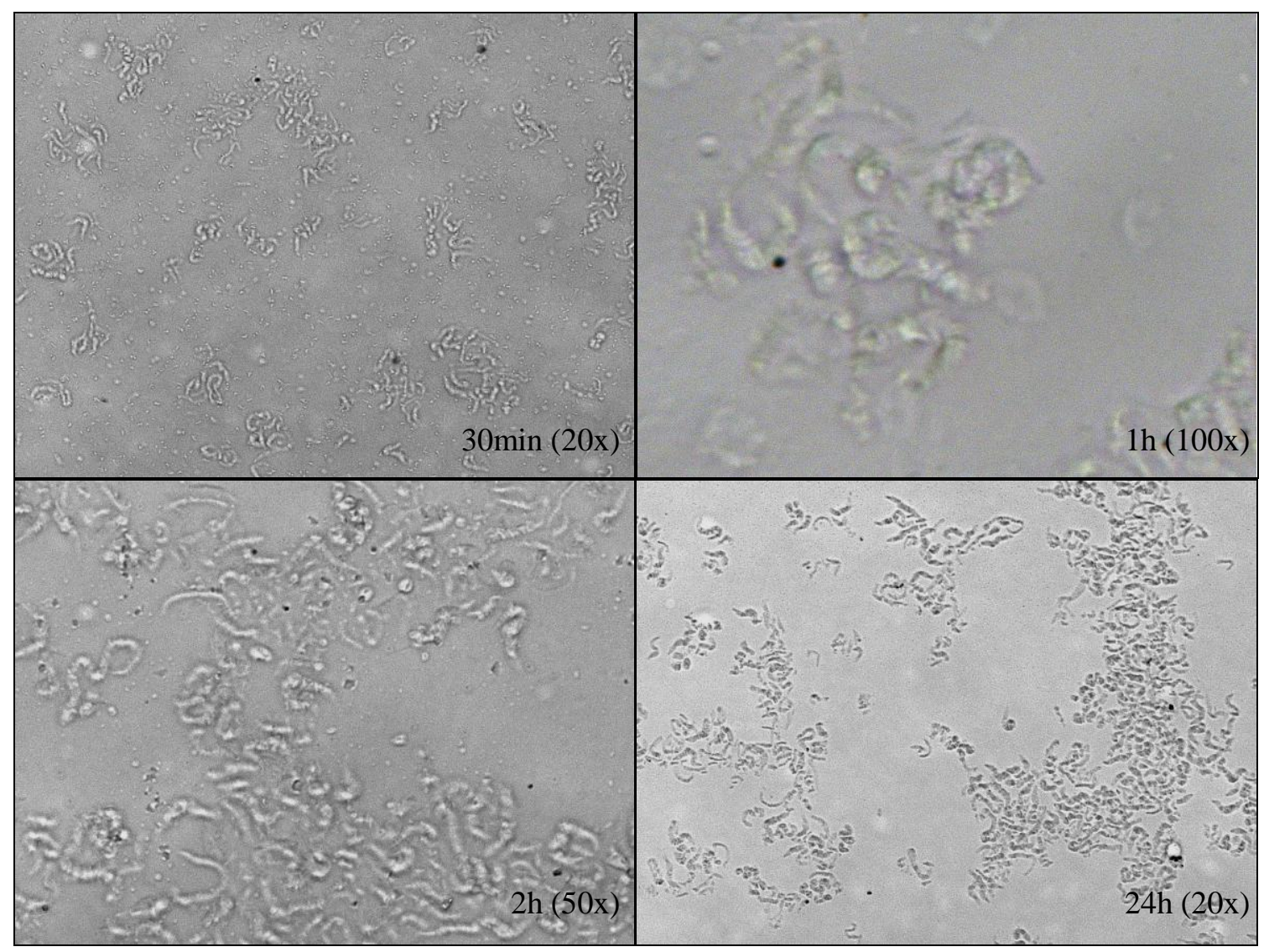

Figura 2 - Parafinas precipitadas após a inserção da amostra no refrigerador (temperatura $\approx 1^{\circ} \mathrm{C}$ ).

A Figura 3 apresenta as microscopias do modelo com 5\% em massa de parafinas isoladas solubilizadas na matriz inerte, durante o resfriamento $\left(80^{\circ} \mathrm{C}\right.$ a $\left.5^{\circ} \mathrm{C}\right)$ e a respectiva ampliação da imagem. 


\section{9 a 22 de outubro de 2014 \\ Florianópolis/SC}

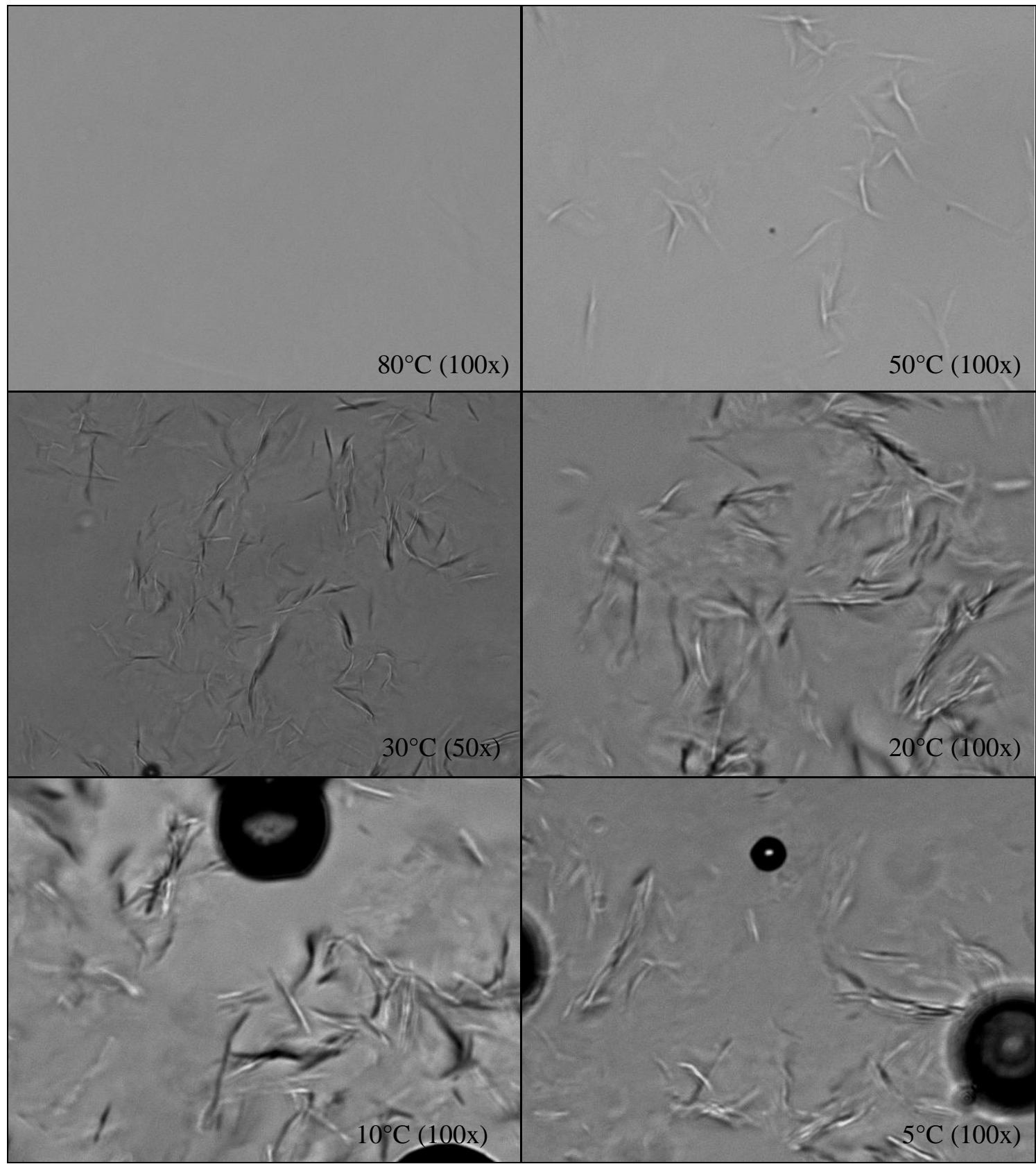

Figura $3-5 \%$ em massa de parafinas isoladas solubilizadas em matriz inerte durante processo de resfriamento a $0,7^{\circ} \mathrm{C} / \mathrm{min}$, de $80^{\circ} \mathrm{C}$ a $5^{\circ} \mathrm{C}$.

É possível verificar o aumento de parafinas precipitadas em função da diminuição da temperatura. As imagens referentes a $10^{\circ} \mathrm{C}$ e $5^{\circ} \mathrm{C}$ apresentam círculos escuros, que são bolhas de ar oriundas da aeração promovida pela agitação da solução viscosa. A morfologia observada é semelhante a bastões finos e longos, o que sugere uma estrutura ortorrômbica. A literatura indica que para modelos de parafinas isoladas obtenham-se estruturas semelhantes à placas (KANÉ et al, 2003), 
entretanto esta relação é válida para altas concentrações de parafínas no meio. A hipótese para este comportamento é portanto, a baixa concentração de parafinas na matriz, impossibilitando a geração de placas (forma hexagonal).

Comparando as Figuras 1 e 3 podemos notar uma pequena semelhança entre as parafinas precipitadas no óleo cru e no sistema modelo. Ambas possuem estruturas alongadas e se aglomeram umas próximas as outras, formando "redes". Entretanto as parafinas no petróleo cru são curvilíneas, enquanto que as parafinas do sistema modelo são lineares.

\section{CONCLUSÃO}

Os dados da TIAC obtidos por DSC são coerentes com o aparecimento de precipitados no óleo cru. Os cristais de parafina, tanto do óleo cru, quanto do sistema modelo, caracterizam-se por serem alongadas e passíveis de aglomeração. As parafinas de óleo cru apresentam aparentemente um aspecto rugoso.

Mais estudos devem ser feitos acerca da morfologia das parafinas de petróleo, bem como os fatores que exercem influência sobre sua estrutura como taxa de resfriamento e condições de agitação. As próximas etapas deste trabalho abrangem estudos de morfologia de parafinas em emulsões, variações das condições experimentais, como presença e ausência de agitação, e variações na taxa de resfriamento.

\section{REFERÊNCIAS}

AGÊNCIA NACIONAL DO PETRÓLEO, GÁS NATURAL E BIOCOMBUSTÍVEIS, Anuário Estatístico Brasileiro do Petróleo, Gás Natural e Biocombustíveis 2013. Disponível em: <http://www.anp.gov.br/?pg=66833>. Acesso em: 05 mar. 2014.

HAMMAMI, A.; RAINES, M. A. Paraffin deposition from crude oils: comparison of laboratory results with field data. SPE Journal. v. 4, n. 1, p. 9-18, mar. 1999.

KANÉ, M. et al. Morphology of paraffin crystals in waxy crude oils cooled in quiescent conditions and under flow. Fuel. v. 82, n. 2, p. 127-135. 2003.

LÉTOFFE, J. M. et al. Crude oils: characterization of waxes precipitated on cooling by d.s.c. and thermomicroscopy. Fuel, v. 74, n. 6, p. 810-817, 1995.

LI, H.; ZHANG, J. A generalized model for predicting non-newtonian viscosity of waxy crude as a function of temperature and precipitated wax. Fuel. v. 82, p. 1387-1397, 2003.

ZBIK, M.; HORN, R. G.; SHAW, N. AFM study of paraffin wax surfaces. Colloids and Surfaces A: physicochemical and engineering aspects. v. 287, p. 139-146, 2006. 
PEDERSEN, K. S.; RONNINGSEN, H. P. Effect os precipitated wax on viscosity - a model for predicting non-newtonian viscosity of crude oils. Energy \& Fuels. v. 14. p. 43-51, 2000. 